\title{
Population Psychiatric Medication Prescription Rates following a Terrorist Attack
}

\author{
Charles DiMaggio, PhD; ${ }^{1}$ Sandro Galea, MD; ${ }^{2}$ Paula A. Madrid, PsyD ${ }^{3}$
}

1. Assistant Professor, Department of Epidemiology, Columbia University Mailman School of Public Health, New York, New York USA

2. Associate Professor, Department of Epidemiology, University of Michigan School of Public Health, Ann Arbor, Michigan USA

3. Director, The Resiliency Project, National Center for Disaster Preparedness, Columbia University Mailman School of Public Health, New York, New York USA

Correspondence:

Charles DiMaggio, PhD

Department of Epidemiology

Columbia University Mailman School of Public Health

722 West 168 Street, Rm 1117

New York, NY 10032 USA

E-mail: cjd11@columbia.edu

Funded by the Centers for Disease Control and Prevention Health Protection Research Initiative Grant Number 1 K01 C000494.

Keywords: 11 September 2001; New York; psychiatric medication; prescription rates; terrorist attack

\section{Abbreviations: \\ DMR $=$ Disaster Medicaid Relief \\ MAX $=$ Medicaid Analytic Extract \\ $\mathrm{PTSD}=$ post-traumatic stress disorder \\ SSRI = selective serotonin reuptake inhibiter \\ WTC $=$ World Trade Center}

Received: 27 April 2007

Accepted: 01 June 2007

Revised: 04 June 2007

Web publication: 18 December 2007

\begin{abstract}
Introduction: While several population-based studies have documented behavioral health disturbances following terrorist attacks, a number of mental health service utilization analyses present conflicting conclusions.

Purpose: The purpose of this study was to determine if mental health service utilization increased following a terrorist attack by assessing changes in psychoactive drug prescription rates.

Methods: The rate of selective serotonin reuptake inhibitor (SSRI) prescriptions was measured among New York State Medicaid enrollees before and after the terrorist attacks of 11 September 2001. The association between geographic proximity to the events and changes in the rate of SSRI prescriptions around 11 September 2001 was assessed.

Results: From September to December 2001, among individuals residing within three miles of the World Trade Center site, there was an $18.2 \%$ increase in the SSRI prescription rate compared to the previous eight-month period $(p=0.0011)$. While there was a 9.3\% increase for non-New York City residents, this change was not statistically significant $(p=0.74)$.

Conclusions: There was a quantifiable increase in the dispensing of psychoactive drugs following the terrorist attacks of 11 September 2001, and this effect varied by geographic proximity to the events. These findings build on the growing body of knowledge on the pervasive effects of disasters and terrorist events for population health, and demonstrate the need to include mental and behavioral health as key components of surge capacity and public health response to mass traumas.
\end{abstract}

DiMaggio C, Galea S, Madrid PA: Population psychiatric medication prescription rates following a terrorist attack. Prehospital Disast Med 2007;22(6):479-484.

\section{Introduction}

The behavioral consequences of terrorist incidents have received considerable attention. A recent meta-analysis of psychopathology in the aftermath of terrorism found that the prevalence of post-traumatic stress disorder (PTSD) in directly-affected populations in the year following a terrorist incident ranges from $12 \%$ to $16 \% .^{1}$ Much of the recent interest in the consequences of terrorism has been informed by concerns arising from the 1995 Oklahoma City bombing, the terrorist attacks of 11 September 2001 in the United States, and the more recent Madrid 2004 and London 2005 bombings. Several reports have documented substantial psychopathology has occurred after these attacks in each of the respective cities..$^{2-5}$ However, despite a substantial and growing body of evidence about psychopathology after these incidents, research on health service utilization after terrorist incidents has been limited.

Several studies have documented psychopathology in New York City residents after these attacks. In one study, 7.5\% of residents of Manhattan reported symptoms consistent with PTSD in the first month after the terrorist attacks. ${ }^{3}$ Twenty percent of residents living in close proximity to the events met the criteria for PTSD during the same time period. ${ }^{6}$ Other studies have shown that the prevalence of anxiety-related diagnoses in the population of 
New York City's Chinatown, which is located in the immediate vicinity of the World Trade Center (WTC), ${ }^{7}$ may have been as high as $50 \%$.

Despite this well-documented prevalence of psychopathology in New York City and the surrounding area, there have been few analyses of mental health service utilization after this attack. The results from the existing work have been conflicting. Surveys of self-reported health service utilization have documented increased need for psychiatric and emergency care. ${ }^{8,9}$ One study, using data from the Veteran's Healthcare Administration facilities in New York and New Jersey, showed a greater than expected mental health service utilization after the 11 September 2001 attacks on New York City. ${ }^{10}$ Several other papers have documented a high prevalence of utilization of mental health services through Project Liberty, a free service established by federal, state, and local public health authorities, to provide mental health services in the aftermath of the 11 September 2001 terrorist attacks. ${ }^{11-14}$ However, in contrast, other studies have demonstrated that there was no significant increase in the utilization of mental health services for the treatment of PTSD among military veteran's in the New York City area, ${ }^{15}$ a national sample of those admitted to a specialized intensive PTSD treatment program for military veterans during that period did not have significantly worse symptomatology than was observed in previous years. ${ }^{16}$

Research on medication utilization following these terrorist attacks also has been conflicting. One report indicated an approximately $5 \%$ statistically significant increase in national psychotropic drug use in the weeks following 11 September 2001. ${ }^{17}$ Another study reported only small, non-significant increases in anti-depressant use among employed members of a private insurance plan impacted by the events of 11 September 2001. ${ }^{18}$

This study follows up and expands on a recent preliminary letter describing the rate of selective serotonin reuptake inhibitor (SSRI) prescriptions among New York State Medicaid enrollees before and after the terrorist attacks of 11 September 2001, and assess the association between geographic proximity to the events and potential changes in the rate of SSRI prescriptions around 11 September 2001. ${ }^{19}$

\section{Methods}

In order to determine persons eligible for Medicaid, data from Medicaid Analytic Extract (MAX) files for New York State residents for 2000 and 2001 were used. ${ }^{20}$ These are a complete set of person-level data files on all New York State residents who received Medicaid-funded inpatient, outpatient, and long-term care service utilization, including prescription drug use. Information on patient identifiers, demographics, eligibility status by month, and prescription drug information that included dates of service and a ninecharacter drug identifier based on the Food and Drug Administration national drug code were collected. ${ }^{21}$

All Medicaid eligible patients in the MAX files were matched to records indicating SSRI prescriptions using the prescription drug information code and the Cerner Lexicon database. ${ }^{22}$ The first five characters refer to the drug manufacturer or packager, the second four digits refer to the product. The SSRIs considered for this study were: (1) citalopram (Celexa, Cipramil, Emocal, Sepram); (2) escitalopram oxalate (Lexapro, Cipralex, Esertia); (3) fluoxetine (Prozac, Fontex, Seromex, Seronil, Sarafem, Fluctin (EUR)); (4) fluvoxamine maleate (Luvox, Faverin); (5) paroxetine (Paxil, Seroxat, Aropax, Deroxat); (6) sertraline (Zoloft, Lustral, Serlain); and (7) trazodone (Desyrel).

Four mutually exclusive geographic areas were created that were progressively more distant from the WTC. The first area included all geographic ZIP code tabulations areas whose centroids were contained within a three-mile radius of a centroid located in the 10007 ZIP code tabulation area that corresponded to the intersection of Church and Vecsey Streets in lower Manhattan, where the WTC complex was located. The second area consisted of ZIP code tabulation areas $>3$ miles but $<10$ miles from the WTC. The third area consisted of ZIP code tabulation areas $>9$ miles, but within the geographic confines of New York City. The fourth area was made up of non-New York City ZIP code tabulation areas. All persons in the database for whom a ZIP code was available were geocoded to one of these four areas.

Four week-based time periods were considered for analysis: (1) Period 1, the week beginning 01 January 2000 to the week ending 16 September 2000; (2) Period 2, the week beginning 17 September 2000 until the week ending 30 December 2000; (3) Period 3, the week beginning 31 December 2000 to the week ending 15 September 2001; and (4) Period 4, the week beginning 16 September 2001 to the week ending 29 December 2001. The dates were chosen to capture the post-11 September 2001 period while establishing equal weekly periods for comparisons.

For each geographic area and for each time period, the mean value for the ages and frequency of gender and race/ethnicity of enrollees receiving SSRI prescriptions were calculated. Results were compared across time and geographic area with analysis of variance (ANOVA) using the Tukey correction for continuous variables and twotailed chi square for categorical variables. To create rates, weekly counts of SSRI prescriptions for each geographic area and time period were tabulated and divided by person years of Medicaid eligibility within that geographic area during that time period. The rates were calculated by area and time with 95\% confidence intervals and percent changes from across similar time periods for each geographic area were determined.

The weekly rates of SSRI prescriptions for New York Medicaid recipients living within three miles of the WTC site and for those living outside New York City were plotted, applying spline smoothing to highlight trends. Changes in the slope of the plots before and after September 2001 were assessed by analyzing the statistical significance of the difference in the regression slope coefficients, and further analyzed the weekly time series using Box-Jenkins methodology and interrupted times series. ${ }^{23,24}$ The time plots were examined for trend, seasonality, discontinuities and outliers. The auto-correlation plots were examined, and first differencing was applied until the series were stationary as evidenced by examination of autocorre- 


\begin{tabular}{|c|c|c|c|c|}
\hline \multirow{2}{*}{ Time Period } & \multicolumn{4}{|c|}{ Residence in Relation to World Trade Center Site } \\
\cline { 2 - 5 } & $<$ miles & $3-10$ miles & New York City 3-10 miles & Non-New York City \\
\hline $\begin{array}{c}\text { September-October } \\
2001\end{array}$ & $27.1(25.7,28.4)$ & $21.6(20.8,22.4)$ & $23.2(22.5,24.0)$ & $32.7(32.3,33.1)$ \\
\hline $\begin{array}{c}\text { January-September } \\
2001\end{array}$ & $22.9(22.3,23.5)$ & $18.8(18.4,19.2)$ & $20.3(20.0,20.7)$ & $29.9(29.4,30.3)$ \\
\hline $\begin{array}{c}\text { Post- vs. Pre- } \\
\text { September } 2001\end{array}$ & $+18.2 \%$ & $+14.7 \%$ & $+14.5 \%$ & $+9.3 \%$ \\
\hline $\begin{array}{c}\text { September-December } \\
2000\end{array}$ & $21.1(20.4,21.7)$ & $17.4(17.0,17.9)$ & $18.9(18.5,19.2)$ & $28.1(27.7,28.4)$ \\
\hline $\begin{array}{c}\text { Post- vs. Pre- } \\
\text { September } 2000\end{array}$ & $-0.4 \%$ & $-2.3 \%$ & $-2.0 \%$ & $0 \%$ \\
\hline
\end{tabular}

Table 1-Average weekly selective serotonin reuptake inhibiter (SSRI) prescriptions (95\% Confidence Interval) per 1,000 person-years of program eligibility and post vs. pre September calendar year percentage changes by residence and time period. ${ }^{1}$ New York State Medicaid data, 2000-2001.

${ }^{1}$ The week beginning 01 January 2000 to the week ending 16 September 2000; the week beginning 17 September 2000 until the week ending 30 December 2000; the week beginning 31 December 2000 to the week ending 15 September 2001; and the week beginning 16 September 2001 to the week ending 29 December 2001.

lation plots and the results of statistical tests such as the Dickey-Fuller test. Models were fitted and assessed with moving average and/or autoregressive terms, and assessed the fit with the statistical significance of the terms. Evidence of stationarity and fit statistics including root mean square error and Akaike Information Criterion were analyzed.

It also was determined whether there was a significant change in prescriptions (i.e., a sudden, temporary effect, a sudden, permanent effect, a gradual, temporary effect, or a gradual, permanent effect around the time of the attack) by applying interrupt terms to the post-September 2001 period. The effect of the interrupt term was assessed through the statistical significance of its associated $p$-value.

All analyses were conducted with SAS version 9.0 and the SAS Time Series Forecasting System (SAS, Inc., Cary, NC) module. ${ }^{25}$ The study protocol was approved by an Institutional Review Board.

\section{Results}

Among Medicaid enrollees living within three miles of the WTC site for all time periods of interest, mean value of the ages ranged between 51 and 54 years. The majority (59\%) was female, and a sizeable minority $(10-11 \%)$ was Asian. In contrast, the largest minority of black enrollees resided in the geographic zone 3-10 miles from the WTC site. The largest minority of Hispanic enrollees was in the New York City zone $>10$ miles from the site. The majority of non-New York City enrollees (57\%) were white with the means of the ages between 45 and 49 .

There was little change in the demographic composition of Medicaid enrollees within geographic areas across time periods. There were appreciable differences across geographic areas during the same time periods. In Period 4, enrollees living within three miles of the WTC site were on average 5.8 years older than those living outside of New York City $(p<0.0001)$. Similarly, there were differences in gender and race/ethnicity across the geographic areas. Those who lived within a three-mile radius of the WTC site were more likely ( $41.0 \%$ vs. $36.7 \%, p<0.0001)$ to be male. There also was a greater proportion of Asians among Medicaid enrollees living within three miles of the WTC site than among those living outside of New York City during Period 4 ( $11.7 \%$ vs. $1.3 \%, p<0.0001)$.

The average weekly SSRI prescription rates per 1,000 person-years of eligibility for each geographic region and time period are provided in Table 1 . While rates increased from Period 3 to Period 4 for all geographic areas following the terrorist attacks of 11 September 2001, Medicaid enrollees living closest to the WTC site experienced the largest post-September 2001 increase (18.2\%). Among those persons living farther away from the WTC site, there were smaller increases in the prescription rate between Periods 3 and 4 . Those living within 10 miles of the WTC site had a $14.7 \%$ increase, those living further than 10 miles from the WTC site but within New York City had a 14.5\% increase, and non-New York City residents had a 9.3\% increase. In contrast, there were decreases in SSRI prescription rates for these geographic areas between the analogous Periods 1 and 2 in 2000.

The weekly SSRI rate for Medicaid enrollees who lived within a three-mile radius of the WTC site is diagrammed in Figure 1. There was a statistically significant change in the slope of the plot from Periods 1 through 3 (preSeptember 2001) to Period 4 (post-September 2001) $(p=0.01)$. Figure 1 also provides the same information for Medicaid enrollees who lived outside New York City. There was no statistically significant change in the slope of this series following September $2001(p=0.11)$.

In ARIMA $(1,1,1)$ models, which provided the best fit for the time series data, an interrupt term representing a sudden, temporary increase in the prescription rate starting with the first week in November was statistically significant 


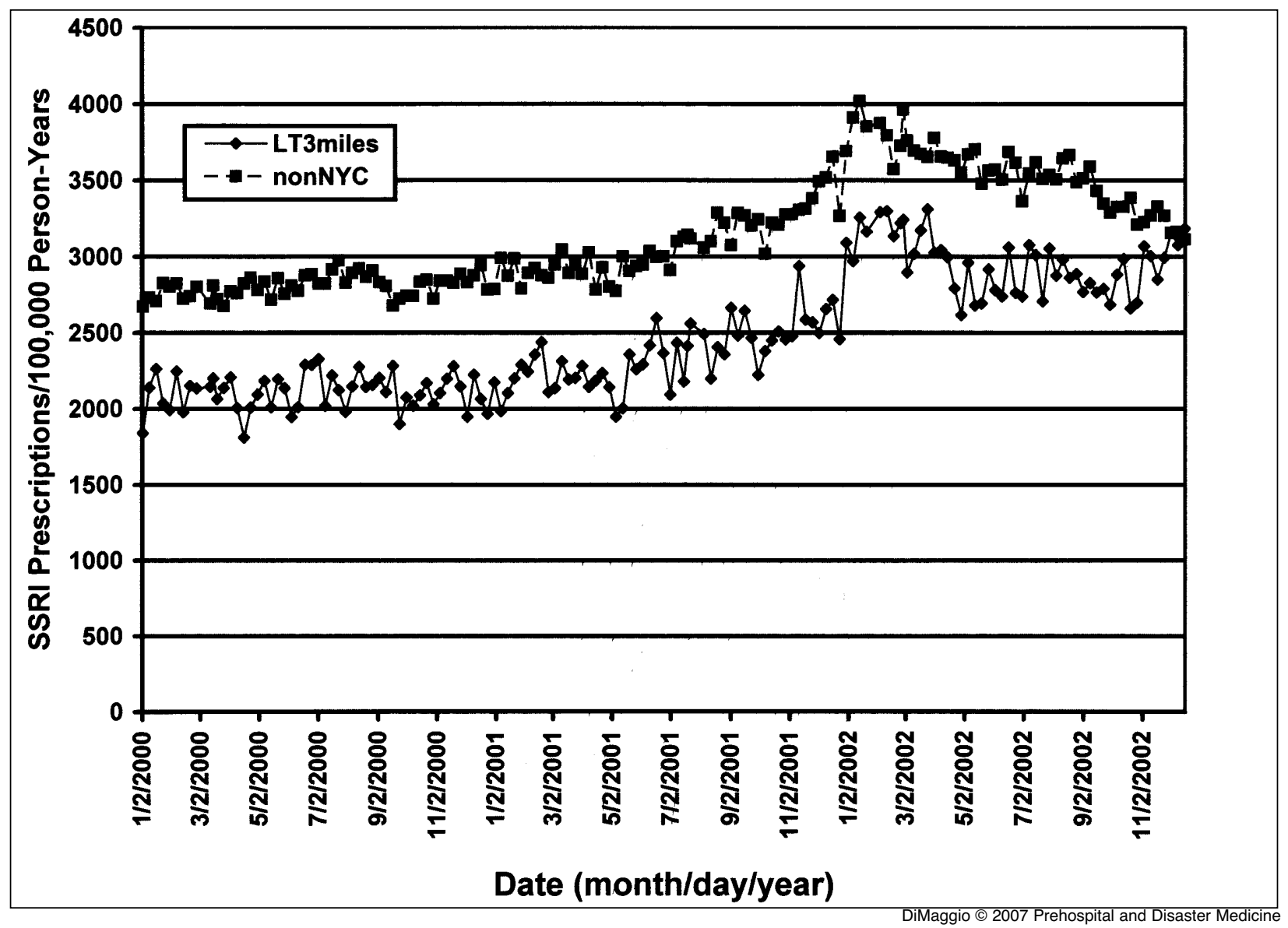

Figure 1-Time series plot, weekly selective serotonin reuptake inhibitor (SSRI) diagnoses

$(p=0.0011)$ for Medicaid recipients residing within three miles of the WTC site. This is illustrated in Figure 2.

Similar models fit to the data for the other three geographic areas did not reveal statistically significant increases in the prescription rate for the same time period. In a similar ARIMA model fit to the data from individuals living outside New York City; the interrupt term representing the post-attack period was not statistically significant $(p=0.74)$.

\section{Discussion}

Selective serotonin reuptake inhibiters are indicated in the treatment of a number of mental health disorders reported to be increased during post-terrorism time periods, including panic disorder and PTSD. ${ }^{26,27}$ This study shows that there was an increase in SSRI medications dispensed in the months following the terrorist attacks of 11 September 2001 and that this effect varied in a dose-response fashion; the increase in amount dispensed increased in geographic areas closer to the site of the attacks.

Healthcare utilization following crises such as disasters and terrorist attacks is difficult to measure. Service may be disrupted and administrative functions curtailed. Fear of violence may cause people to stay at home. ${ }^{28}$ In addition, psychiatric conditions may be overshadowed by physical complaints after a catastrophic event, and it has been suggested that there are substantial unmet mental health needs after such events. ${ }^{29,30}$
These factors may explain why several studies conducted after disasters have failed to document an increase in service utilization, although several population-based surveys have shown increased behavioral and mental health pathology following such events. ${ }^{6-9,15,16,18}$ However, this study is consistent with population-based reports of signs and symptoms consistent with increases in PTSD and anxiety-related diagnoses in New York City neighborhoods within close proximity of the WTC site as well as with selfreports of increased psychiatric medication use. ${ }^{6-8}$

These findings are in contrast to a well-conducted report of little or no increased psychotropic medication utilization among a group of employed insurance plan members affected by the terrorist attacks. ${ }^{18}$ The authors suspect that this difference may be due in part to a "healthy worker effect". The population of Medicaid enrollees would be expected to have a high proportion of unemployed and underemployed individuals and likely would be less healthy overall than would a group of employed persons. It has been suggested in several studies, that low socioeconomic status and unemployment are risk factors for mental health pathology after mass trauma. ${ }^{31,32}$ Thus, it is possible that a post-terrorism epidemiological analysis of employed insurance beneficiaries is less likely than one conducted on a group of Medicaid enrollees to demonstrate increased psychiatric medication use.

Medicaid is a federal, state, and in New York State, a locally funded health insurance program with income, age, 


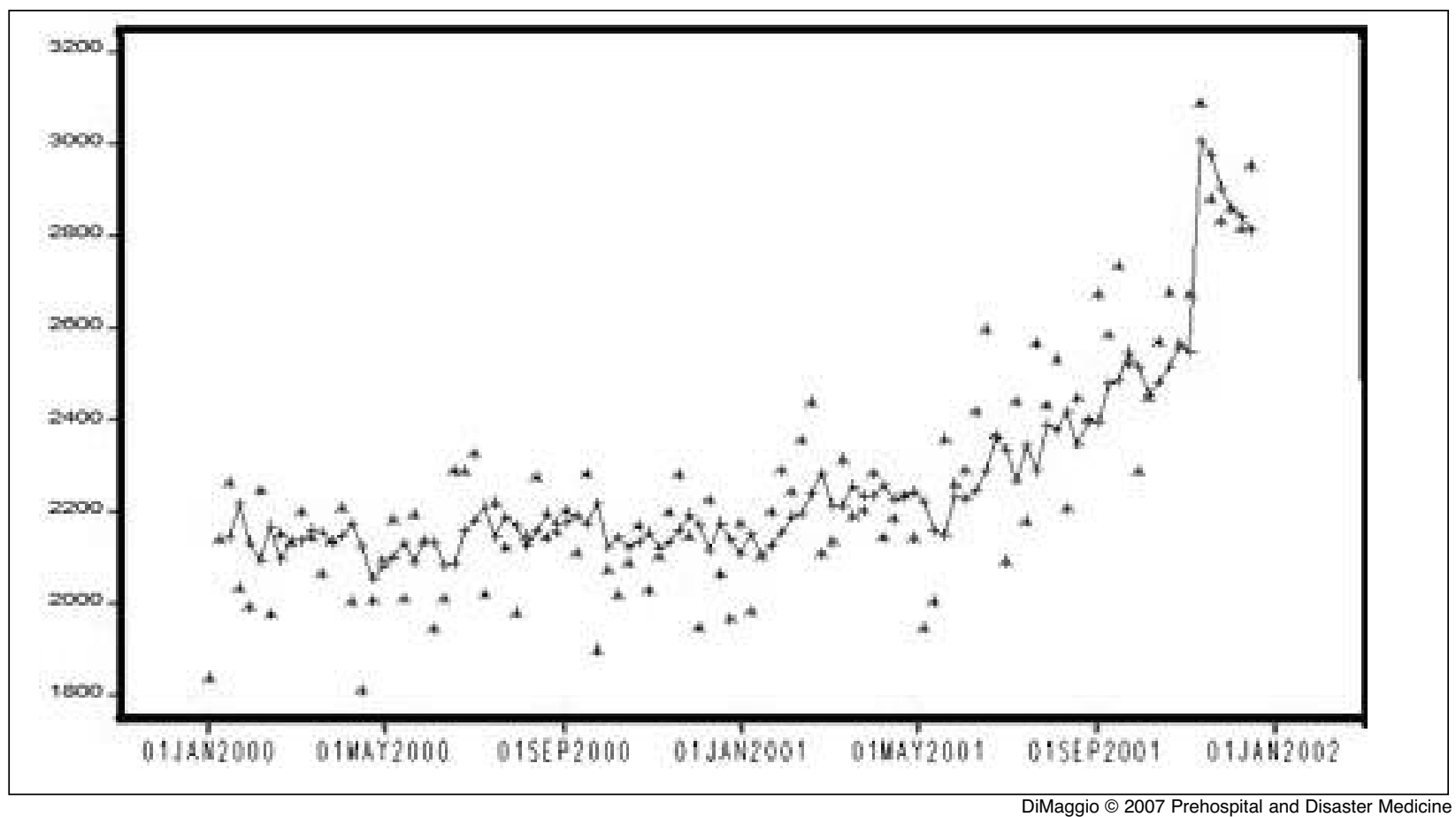

Figure 2-Interrupted times series model, selective serotonin reuptake inhibiter (SSRI) prescription rate, New York State Medicaid recipients residing with three miles of the World Trade Center site. [AU: please provide data so we can produce high-resolution figure]

and disability requirements. These requirements may change over the course or time and for example, may have been responsible for declines in prescription fills in the latter part of 2000. In response to communication and computer infrastructure disruptions following the terrorist attacks of 11 September 2001, program officials implemented the Disaster Medicaid Relief (DMR) program. Participants received four months of coverage based on a simplified one-page application. Enrollments began two weeks after the terrorist attacks of 11 September 2001. The enrollment period ran for the four-month period from October 2001 to the end of January 2002.33 The 342,362 persons who enrolled in DMR represented a $12 \%$ increase over the existing 2.85 million pre-existing enrollees. ${ }^{34}$ Forty-four percent of these individuals transitioned to the regular Medicaid program at the end of the four months. Therefore, it is possible that some of the post- 11 September increase in SSRI dispensing may be explained, in part, by the wider availability of free services through DMR. The authors attempted to control for this by basing the weekly time series results on rates per person-years of Medicaid eligibility for that week. This approach should have controlled for the increased number of eligible individuals by including them in the denominator of the rate.

That Medicaid beneficiaries residing outside of New York City differed from New York City beneficiaries may have accounted for the overall higher base-line rate of SSRI fill rates in areas outside of New York City. The authors attempted to control for social and demographic characteristics of the population under study that may have been due to secular changes or to movement of persons out of NYC after the terrorist attacks through statistical adjusting for trend, seasonality, and autocorrelation of observations.

Trends that could have affected the results are visible in Figures 1 and 2. Increases in SSRI prescription fill rates for all geographic areas appeared to begin some time in May of 2001, pre-dating the attacks. This may have been due to changes in benefit definitions or the inclusion of additional SSRIs in Medicaid formularies. Use of the ARIMA methods allowed the control of such trends by reducing the data to a stationary time series before investigating the significance of changes following the terrorist attacks of 11 September 2001.

Similar time-series approaches have been utilized to examine such potential post-terrorism effects as changes in divorce rates following the Oklahoma City bombing of 1995 and psychiatric emergencies in San Francisco following the terrorist attacks of 11 September 2001..$^{35,36}$ While these results cannot demonstrate causation, they are consistent with the evidence for the increase in mental health pathology after terrorist attacks, and have the strength of a plausible gradient effect.

\section{Conclusions}

These results indicate that there may have been quantifiable increases in dispensing of psychoactive drugs following the terrorist attacks of 11 September 2001. Only three months of post-attack data were examined. New York Medicaid MAX files for 2002 have not yet been released by the Centers for Medicaid Services. ${ }^{37}$ Future analysis must 
assess whether the increased SSRI utilization among nearby residents of the WTC area was short-lived or sustained. However, this is the first report of a quantifiable increase in psychoactive drug use associated with physical proximity to these attacks.

Behavioral and emotional consequences extending beyond those immediately affected in fact, are the intent of terrorists. Public health efforts to mitigate the consequences of these disasters then must be based on an under-

\section{References}

1. DiMaggio C, Galea S: The behavioral consequences of terrorism: a metaanalysis. Acad Emerg Med 2006;13(5):559-566.

2. North CS, Nixon SJ, Shariat S, Mallonee S, McMillen JC, Spitznagel EL, Smith EM: Psychiatric disorders among survivors of the Oklahoma City bombing. JAMA 1999;282(8):755-762.

3. Galea S, Ahern J, Resnick H, Kilpatrick D, Bucuvalas M, Gold J, Vlahov D: Psychological sequelae of the September 11 terrorist attacks in New York City. N Engl J Med 2002;346(13):982-987.

4. Munoz M, Crespo M, Perez-Santos E, Vazquez JJ: Early psychological consequences of the March 11, 2004, terrorist attacks in Madrid, Spain. Psychol Rep 2005;97(3):907-920.

5. Rubin GJ, Brewin CR, Greenberg N, Simpson J, Wessely S: Psychological and behavioural reactions to the bombings in London on 7 July 2005: Cross sectional survey of a representative sample of Londoners. BMJ 2005;331(7517):606.

6. Galea S, Resnick H, Ahern J, Gold J, Bucuvalas M, Kilpatrick D, Stuber J, Vlahov D: Posttraumatic stress disorder in Manhattan, New York City, after the September 11th terrorist attacks. J Urban Health 2002; 79(3):340-53.

7. Chen H, Chung H, Chen T, Fang L, Chen JP: The emotional distress in a community after the terrorist attack on the World Trade Center. Community Ment Health J 2003;39(2):157-165.

8. Boscarino JA, Galea S, Adams RE, Ahern J, Resnick H, Vlahov D: Mental health service and medication use in New York City after the September 11, 2001, terrorist attack. Psychiatr Serv 2004;55(3):274-283.

9. Fagan J, Galea S, Ahern J, Bonner S, Vlahov D: Relationship of self-reported asthma severity and urgent health care utilization to psychological sequelae of the September 11, 2001 terrorist attacks on the World Trade Center among New York City area residents. Psychosom Med 2003;65(6):993-996.

10. Weissman EM, Kushner M, Marcus SM, Davis DF: Volume of VA patients with posttraumatic stress disorder in the New York metropolitan area after September 11. Psychiatr Serv 2003;54(12):1641-1643.

11. Felton CJ: Project Liberty: A public health response to New Yorkers' mental health needs arising from the World Trade Center terrorist attacks. J Urban Health 2002;79(3):429-433.

12. Moynihan PJ, Levine JM, Rodriguez O: The experiences of Project Liberty crisis counselors in the Bronx. Community Ment Health J2005;41(6):665-673.

13. Rudenstine S, Galea S, Ahern J, Felton C, Vlahov D: Awareness and perceptions of a communitywide mental health program in New York city after September 11. Psychiatr Serv 2003;54(10):1404-1406.

14. Siegel C, Wanderling J, Laska E: Coping with disasters: Estimation of additional capacity of the mental health sector to meet extended service demands. JMent Health Policy Econ 2004;7(1):29-35.

15. Rosenheck R, Fontana A: Use of mental health services by veterans with PTSD after the terrorist attacks of September 11. Am J Psychiatry 2003;160(9):1684-1690.

16. Rosenheck RA, Fontana A: Post-september 11 admission symptoms and treatment response among veterans with posttraumatic stress disorder. Psychiatr Serv 2003; 54(12):1610-1617

17. Kettl P, Bixler E: Changes in psychotropic drug use after September 11, 2001. Psychiatr Serv 2002; 53(11):1475-1476 standing of the scope of their consequences. As eloquently stated by Noji, "[the effort] required to collect the information necessary to provide apt and well-directed aid is more than justified by the improved results". ${ }^{38}$ These analyses are part of such an effort. These findings should build on the growing body of knowledge on the pervasive effects of disasters and terrorist events for population health and the need to include mental and behavioral health as key components of surge capacity and public health response.

18. McCarter L, Goldman W: Use of psychotropics in two employee groups directly affected by the events of September 11. Psychiatr Serv 2002;53(11):1366-1368.

19. DiMaggio C, Galea S, Madrid P: SSRI prescription rates after a terrorist attack. Psychiatr Serv 2006;57(11):1656-1657.

20. Centers for Medicare and Medicaid Services: Medicaid Analytic eXtract (MAX) General Information. Washington: Centers for Medicare and Medicaid Services, 2006.

21. United States Food and Drug Administration (USFDA): The National Drug Code Directory. Edited by Administration UFaD. Washington: US Food and Drug Administration, 2006.

22. Cerner: Multum. Denver: Cerner, 2006.

23. Chatfield C: The Analysis of Time Series: An Introduction. Boca Raton, FL, Chapman \& Hall/CRC, 2003.

24. Diggle P: Time Series: A Biostatistical Introduction. Oxford [England] New York, Clarendon Press; Oxford University Press, 1990.

25. Brocklebank JC, Dickey DA, Brocklebank JC: SAS for Forecasting Time Series. Cary, NC, SAS Institute; John Wiley, 2003.

26. Gliatto MF: Generalized anxiety disorder. Am Fam Physician 2000;62(7):1591-1600,1602.

27. Lange JT, Lange CL, Cabaltica RB: Primary care treatment of post-traumatic stress disorder. Am Fam Physician 2000;62(5):1035-1040, 1046.

28. Beare JM, Burrows D, Merrett JD: The effects of mental and physical stress on the incidence of skin disorders. British Journal of Dermatology 1978; 98(5):553-558.

29. Curran PS, Gregg W: Psychiatric aspects of terrorist violence in Northern Ireland (1969 to 1989). Med Leg J 1990;58(Pt 2):83-96.

30. Stuber J, Galea S, Boscarino JA, Schlesinger M: Was there unmet mental health need after the September 11, 2001 terrorist attacks? Soc Psychiatry Psychiatr Epidemiol 2006;41(3):230-240.

31. Norris FH, Friedman MJ, Watson PJ, Byrne CM, Diaz E, Kaniasty K: 60,000 disaster victims speak: Part I. An empirical review of the empirical literature, 1981-2001. Psychiatry 2002;65(3):207-239.

32. Montazeri A, Baradaran H, Omidvari S, Azin SA, Ebadi M, Garmaroudi G, Harirchi AM, Shariati M: Psychological distress among Bam earthquake survivors in Iran: a population-based study. BMC Public Health 2005;5:4.

33. Perry M: New York's Disaster Relief Medicaid: Insights and Implications for Covering Low-Income People. Washington: Kaiser Commission on Medicaid and the Uninsured in Collaboration with the United Hospital Fund, 2002.

34. Calicchia M, Greene R, Lee E, Warner M: Disaster Relief Medicaid Evaluation Project. Ithaca, Cornell University, School of Industrial and Labor Relations, 2005.

35. Nakonezny PA, Reddick R, Rodgers JL: Did divorces decline after the Oklahoma City bombing? Journal of Marriage and Family 2004;66:90-100.

36. Catalano RA, Kessell ER, McConnell W, Pirkle E: Psychiatric emergencies after the terrorist attacks of September 11, 2001. Psychiatr Serv 2004;55(2):163-166.

37. Research Data Assistance Center: What's New: MAX 2002 Files. Minneapolis: University of Minnesota, 2006.

38. Noji EK, Sivertson KT: Injury prevention in natural disasters: A theoretical framework. Disasters 1987;11(4):290-296. 